\title{
Continuous thoracic paravertebral block reduces the risk of supraventricular arrhythmias after minimally invasive mitral valve repair
}

Hiroki Taenaka', Sho Carl Shibata',Yuji Fujino'

1Department of Anaesthesiology and Intensive Care Medicine, Osaka University Graduate School of Medicine

大阪大学 OSAKA UNIVERSITY

\section{BACKGROUND}

Thoracic paravertebral block (TPVB) has been shown to provide excellent postoperative analgesia after minimally invasive cardiac surgery with lateral thoracotomy ${ }^{2}$

Supraventricular arrhythmias (SVAs), including atrial fibrillation are a common complication after cardiac surgery and are associated with increased morbidity and mortality ${ }^{3}$.

Both postoperative pain and sympathetic nerve hyperactivity contribute to the development of SVAs ${ }^{5}{ }^{6}$. We hypothesized that continuous TPBV could reduce the occurrence of postoperative SVAs by inhibiting of both components.

We evaluated the effect of continuous TPVB and other possible risk factors on the occurrence of postoperative SVAs in patients undergoing minimally invasive mitral valve repair at our institution.

\section{MATERIALS AND METHODS}

After institutional review board approval, we performed a retrospective record based review of all patients who underwent minimally invasive mitral valve repair at our center between March $20 \mathrm{II}$ and October $20 \mathrm{I} 6$.

Supraventricular arrhythmia was defined as at least I hour-duration of either atrial fibrillation, junctional rhythm, or atrial premature complex.

We investigated the relationship between the incidence of SVAs with continuous TPVB, age, sex, and duration of aortic cross clamp time.A multivariate analysis was performed to identify independent risk factors.

\section{RESULTS AND DISCUSSIONS}

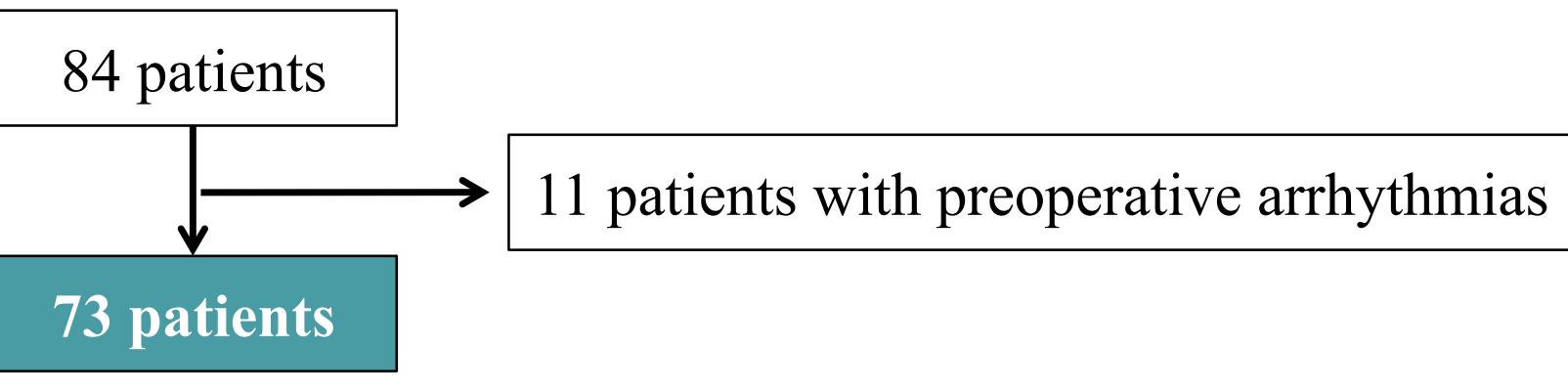

We included a total of 84 patients in our 5 year study period. After excluding those patients who did not meet our criteria, 73 patients were included in the final analysis.

\section{RESULTS AND DISCUSSIONS}

Table I. The patient characteristics

\begin{tabular}{|c|c|c|c|}
\hline VARIABLES & $\begin{array}{l}\text { SVAS } \\
(n=42)\end{array}$ & $\begin{array}{c}\text { No SVAs } \\
(n=3 \text { I) }\end{array}$ & $\mathbf{P}$ \\
\hline Female, n (\%) & $21(50)$ & $7(23)$ & 0.02 \\
\hline Age, years (SD) & $52 \pm 4$ & $50 \pm 4$ & $0.5 \mathrm{I}$ \\
\hline $\mathrm{BMI}, \mathrm{kgm}^{-2}(\mathrm{SD})$ & $22 \pm 1$ & $23 \pm 1$ & 0.54 \\
\hline Hypertension, n (\%) & $20(48)$ & 14(52) & 0.72 \\
\hline Diabetes mellitus, n (\%) & $2(5)$ & $4(14)$ & 0.96 \\
\hline$A S A \geq 3, n(\%)$ & $23(55)$ & $15(48)$ & 0.38 \\
\hline Left ventricular ejection fraction, \% (SD) & $69 \pm 3$ & $67 \pm 3$ & 0.13 \\
\hline Aortic cross clumping time, min (SD) & $161 \pm 16$ & $133 \pm 19$ & 0.03 \\
\hline Surgery duration, $\mathrm{h}$ (SD) & $338 \pm 24$ & $296 \pm 28$ & 0.02 \\
\hline Continuous TPVB, n (\%) & $28(67)$ & $26(84)$ & 0.08 \\
\hline Intraoperative transfusion volume, $\mathrm{ml}(\mathrm{SD})$ & $941 \pm 186$ & $686 \pm 217$ & 0.08 \\
\hline
\end{tabular}

- Fourty-two patients were diagnosed with SVA (57.5\%).

- SVA commonly occurred on the first postoperative day $(52.4 \%)$.

- Catecholamines were either discontinued or maintained at very low doses in all cases.

- Potassium chloride, landiolol, magnesium, amiodarone are administered to treat SVAs in 33, 6, 5, 3 cases respectively.

Table 2. Results for independent risk factor of SVAs

\begin{tabular}{|lccc|}
\hline VARIABLES & OR & $95 \% \mathbf{C I}$ & P \\
\hline TPVB & 4.11 & $1.21-16.29$ & 0.02 \\
\hline Age (per yeat) & 1.02 & $0.98-1.07$ & 0.35 \\
\hline Aortic cross clumping time (per min) & 1.02 & $1.00-1.03$ & $<0.01$ \\
\hline
\end{tabular}

- In the multivariate analysis, the risk of SVAs was decreased with continuous TPVB.

- Duration of aortic cross clamp was an independent risk factor of SVAs.

- Increased age was not a significant factor.

\section{CONCLUSIONS}

The use of continuous TPVB was significantly related with a decreased incidence of postoperative SVAs. Duration of aortic cross clamp time was also a significant risk factor. In addition to excellent postoperative pain control, continuous TPVB reduces the risk of SVAs in patients undergoing minimally invasive mitral valve repair.

References

I. Okitsu K et al. (20I5). Heart and Vessels Heart Vessels, 3 I (9), I 484- I 490.

2. Davies RG. (2006). British Journal of Anaesthesia, 96(4), 4I 8-426.

3. Chung MK. (2000). Critical Care Medicine, 28(Supplement), I 36- I 44.

4. Almassi GH et al. (1997). Annals of Surgery, 226(4), 50 I-5 I 3.

5. Hogue CW et al. (2005). Chest, 128:9S- I6S.

6. Bruins $P$ et al. (1997). Circulation, 96(10), 3542-3548. 